
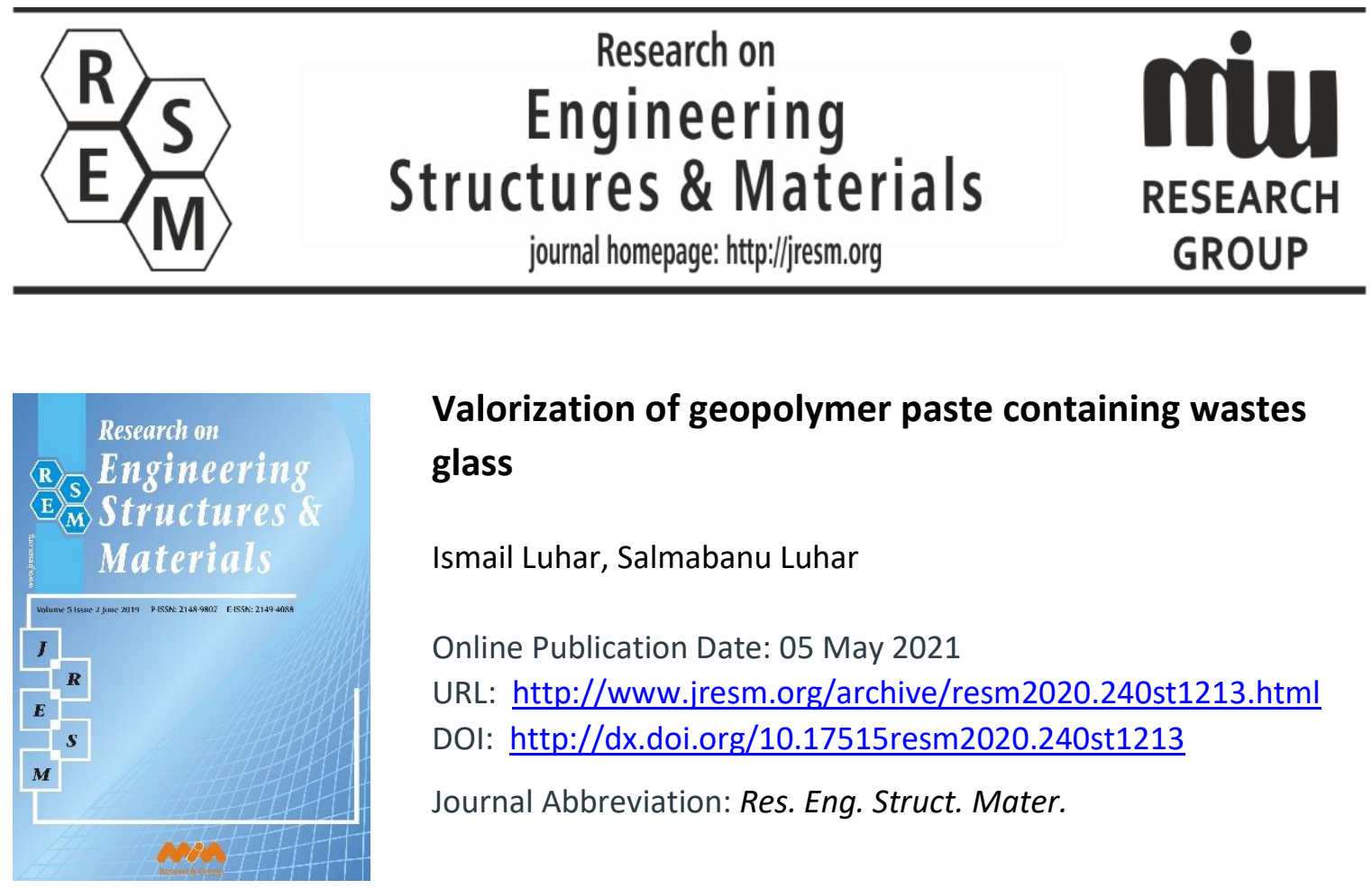

\title{
Valorization of geopolymer paste containing wastes glass
}

Ismail Luhar, Salmabanu Luhar

Online Publication Date: 05 May 2021

URL: http://www.jresm.org/archive/resm2020.240st1213.html

DOI: http://dx.doi.org/10.17515resm2020.240st1213

Journal Abbreviation: Res. Eng. Struct. Mater.

\section{To cite this article}

Luhar I, Luhar S. Valorization of geopolymer paste containing wastes glass. Res. Eng. Struct. Mater., 2021; 7(4): 481-504.

\section{Disclaimer}

All the opinions and statements expressed in the papers are on the responsibility of author(s) and are not to be regarded as those of the journal of Research on Engineering Structures and Materials (RESM) organization or related parties. The publishers make no warranty, explicit or implied, or make any representation with respect to the contents of any article will be complete or accurate or up to date. The accuracy of any instructions, equations, or other information should be independently verified. The publisher and related parties shall not be liable for any loss, actions, claims, proceedings, demand or costs or damages whatsoever or howsoever caused arising directly or indirectly in connection with use of the information given in the journal or related means.

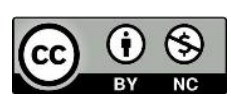

Published articles are freely available to users under the terms of Creative Commons Attribution - NonCommercial 4.0 International Public License, as currently displayed at here (the "CC BY - NC"). 


\title{
Research on Engineering Structures \& Materials
}

journal homepage: http://jresm.org

Review Article

\section{Valorization of geopolymer paste containing wastes glass}

\author{
Ismail Luhar ${ }^{1, a}$, Salmabanu Luhar ${ }^{* 2,3, b}$ \\ ${ }^{1}$ Shri Jagdishprasad Jhabarmal Tibrewala University, Rajasthan, India \\ ${ }^{2}$ Frederick Research Center, Frederick University , Nicosia 1036 , Southern Cyprus \\ ${ }^{3}$ Center of Excellence Geopolymer and Green Technology, School of Materials Engineering, \\ Universiti Malaysia Perlis (UniMAP), Perlis 01000, Malaysia
}

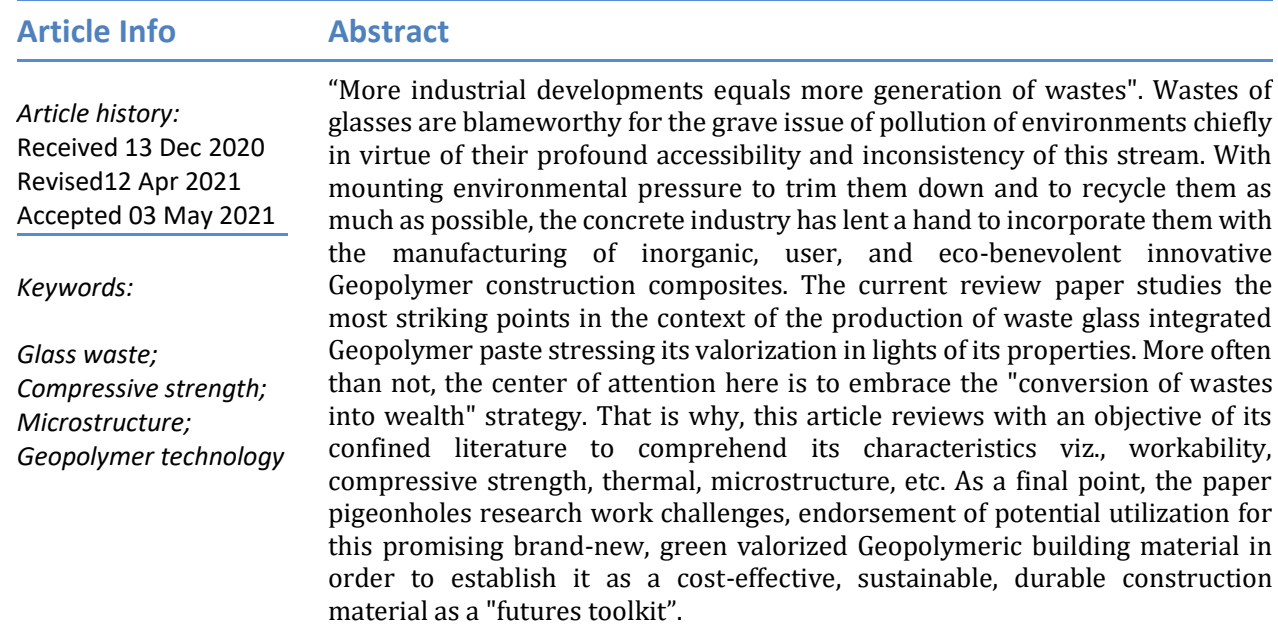

(C) 2021 MIM Research Group. All rights reserved.

\section{Introduction}

An upsurge in industrial developments brought forth the generation of several wastes from industries cropping up a gigantic dilemma for their well-thought-out disposal. Copious landfills of solid glass waste (WG) from a lot more sources are liable to not only environmental but also health jeopardy. Nowadays, glass production is in great demand due to its employment in extensive practical, technological, traditional and decorative applications with the characteristic easiness of formability into any kind of shape viz., packaging, pharmaceuticals, cosmetics; dining tableware, housing and building interior decoration, window panes, optics, etc. Depending upon the resources of generation, the diverse waste glass may be found in the form of solar panel-WG, cullet of WG, modern EWG from E-waste, etc. Often, glass is transparent and a non-crystalline amorphous type solid whereby the atomic structure is deficient of the long-range periodicity as visible crystallized ones. The historically oldest and well-known kinds of brittle but extremely durable manufactured glasses are coined as "silicate glasses" based on their enclosure of the primary component of sand, i.e., Silica [Quartz - Silicon Dioxide $\left.\left(\mathrm{SiO}_{2}\right)\right]$; as well as "Sodalime glass" having roughly $70 \%$ Silica Glass is regarded as inert material in a usual environment that can undergo recycling through an assortment of techniques sans leaving any impression on its chemistry. The different oxide additives bring about diverse colors into the glass. The color in glass may be achieved by supplement homogenously dispersed color centers or ions that are electrically charged. Also, glass can be colored through the

\footnotetext{
${ }^{*}$ Corresponding author: ersalmabanu.mnit@gmail.com a orcid.org/0000-0002-9032-0483; b orcid.org/0000-0002-1129-2825 
addition of metal salts to use it like stained glass windows, glass art objects, etc. Glasses can be poured, formed, extruded, and molded with ease into flat sheets to extremely intricate shapes during production. It is solvable at alkaline $\mathrm{pH}$ values amazingly. More often than not, it is strongly resistant to chemical attacks; however, it can be corroded or dissolved under a few specific conditions. Surprisingly, it is found stronger than most metals with a significant tensile strength owing to its capability to experience reversible compression with no fracture. Thus, the glass is very hard and possesses very inferior thermal expansion with brilliant thermal shock resistance. For these reasons, it is competent enough to survive on immersing in the water when it was red hot resisting elevated temperatures ranging from $1000^{\circ}$ to $1500^{\circ} \mathrm{C}$ as well as chemical weathering. The fused quartz is employed for applications at towering temperatures like furnace and lighting tubes, melting crucibles, etc. Not only have that, the non-biodegradable nature of WG is also a challenge to contaminate soil and waters. However, WG can be subjected to recycling to use it for concrete manufacturing as a replacement of natural restricted aggregate resources helping to protect for their conservation. Recently, WG has attracted researchers to manufacture Geopolymeric composites as an add-on recycled material in Geopolymer paste, mortar, and concretes not only to lower operational energy and $\mathrm{CO}_{2}$ emissions as compared to cement-system, which in turn, lower the challenges of a titanic dilemma of global warming. Having high regard for innovative Geopolymer technology, this has long been documented to offer the potential for incorporation of wastes in producing Geopolymer construction composites. It extends a systematic solution for their disposal dilemma. This is the core reason why geopolymers are dexterous of valorizing quite a lot of pozzolanic wastes from diverse resources of glass rich in Alumina plus Silica. Various researchers have worked on various wastes to be utilized for preparing diverse pastes to apply for construction industries [1-4]. Significantly, the geopolymer emits ninefold low carbon footprint and six times lesser operational energy in comparison to the contemporary cement production process, saving natural limited mineral resources as fuels to achieve towering temperatures for calcination of Limestones - an essential raw material for cement as well as slimming down the earth-heating [6-8]. Little preceding investigations are easy to get to on geopolymer paste with WG-valorization. To date, highly limited investigations have conducted on geopolymerization of pastes integrated with WG or WG-powder or WG- mixes blended with Slag, Fly ash, etc. Momentously, the viability and acceptance of such WG blended Geopolymeric paste must be confirmed by verifying its significant parameters to establish it as a 'sustainable' structural material. For this reason, the present scientometric review aspires to valorize and stimulate the application of waste glass integrated manufacturing of novel geopolymer paste making it over as a "'class' material keeping an eye on its attributes viz., workability, compressive strength, thermal, microstructure, etc. along with challenges and applications to encourage their application as low carbon, reduced operational energy, affordable, durable, sustainable and user-benevolent inorganic polymerized composite in construction and infrastructure industries.

\section{Properties of Geopolymer Composites Incorporated with Glass Wastes}

\subsection{Workability}

Wang et al. [13] have investigated on a study of the engineering attributes of Geopolymer material containing WG and its setting times as represented by Fig. 1 that when the alkaline solution is taken as $0.5 \%$ and the liquid: solid ratio is escalated from 0.50 to 0.55 , the early and final setting times are extended by 87 and 131 minutes respectively. If the liquid: solid ratio is augmented to 0.60 , the initial and final setting times are made longer by 159 and $227 \mathrm{~min}$. Correspondingly. On account of the higher liquid: solid ratio, the alkaline solution is diluted via the water of the alkali metal silicate solution, and hence, the setting time is 
lengthened. When the liquid: solid ratio is 0.55 , and the alkaline solution is kept at $0.5 \%$, the early and final setting times found are $300 \mathrm{~min}$ and $595 \mathrm{~min}$ in that order.

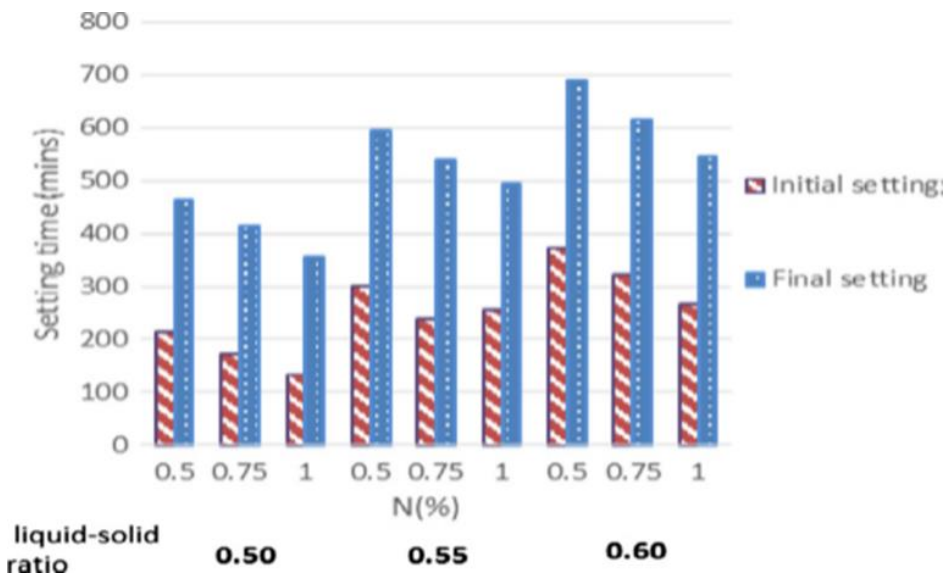

Fig. 1 Setting time of alkali-activated waste glass material [13]

When the alkaline solution boosts to $1 \%$, the early and final setting times are cut down by $45 \mathrm{~min}$. and $100 \mathrm{~min}$. respectively, signaling to an enhance in the alkaline solution that can condense the setting time. Fig. 2 displays that when the alkaline solution is kept at $0.75 \%$, the liquid: solid ratio is 0.50 , and the glass sand substitution level is $0 \%$, the early and final setting times are $171 \mathrm{~min}$. and $413 \mathrm{~min}$., correspondingly. When the glass sand substitution is accelerated to $20 \%$, the initial and final setting times are $321 \mathrm{~min}$. and $616 \mathrm{~min}$., in that order. The upshot reveals that the setting time enhances as the glass Sand substitution escalates. For a reason, the glass sand is water repellent when the glass sand substitution accelerates, the glass sand cannot swiftly submit itself to a poly-reaction with Slag and $\mathrm{OH}$ ions, so the setting time has got extended.

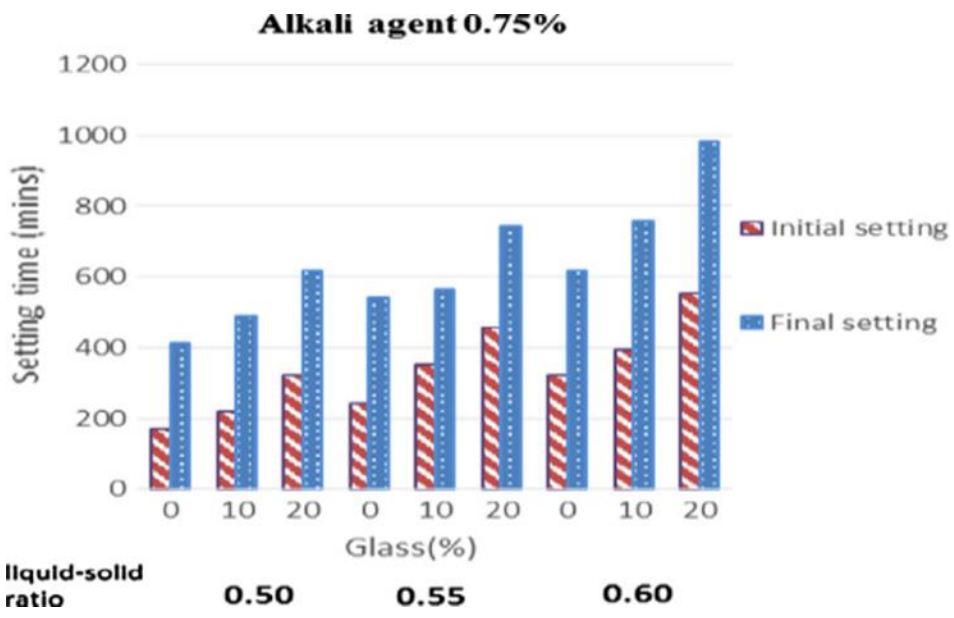

Fig. 2 Impact of glass waste on setting time of geopolymer paste [13]

The study by Torres-Carrasco and Puertas [14], unearthed that the nature of the activator has significantly affected the development of paste strength. Of the solutions they investigated, the least performance was displayed by $\mathrm{NaOH}$ : $\mathrm{Na} 2 \mathrm{CO} 3$ having $\mathrm{pH}=13.3$, with values of $29 \mathrm{MPa}$ as portrayed in Fig. 3, which dropped to $17.1 \mathrm{MPa}$ when $25 \mathrm{~g}$ of WG 
was supplemented to that solution as an option to commercial Sodium Silicate, extending a $\mathrm{pH}$ of 13.4. Because $\mathrm{pH}$ controls Alumino-Silicate dissolution that encourages nucleation or condensation and polymerization, it plays an important role in the activation of the said materials. Even so, while a commercial Sodium Silicate, i.e., water glass, along with a SiO2: Na2O modulus of 0.86 , as well as $\mathrm{pH}$ of 13.8 , was employed, the strength measured was $54 \mathrm{MPa}$. As the liquid: solid ratio, i.e., $\mathrm{L} / \mathrm{S}=0.4$, was the same in every one of the systems, though, when the commercial Sodium Silicate solution was employed, the paste showed a lower consistency. This may have partly described the enhanced mechanical strength monitored [15].
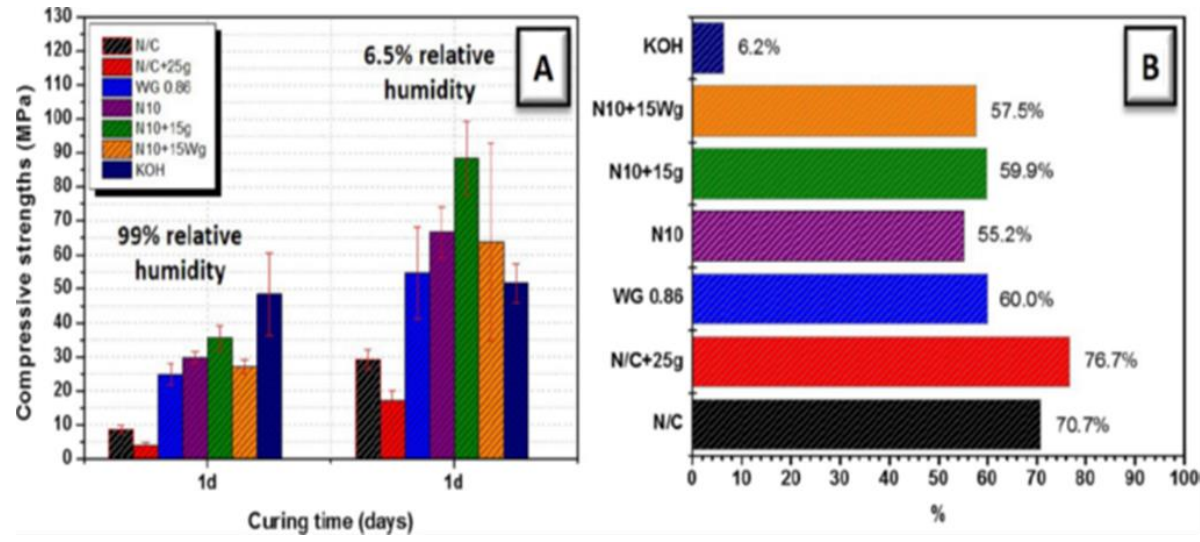

Fig. 3 Compressive strength for waste glass activated with different activating solutions [14]

What is more, the reactivity of Si from a commercial Sodium Silicate is superior to the dissolve Si from WG. While the glass pastes were activated with a high $\mathrm{OH}$ - concentration eg. typically utilized to activate Fly ash, mechanical strength has increased. The optimum outcomes were monitored for the WG-NaOH solution $(\mathrm{N} 10+15 \mathrm{~g})$, which exhibited the strength of $88 \mathrm{MPa}$.

Torres-Carrasco and Puertas [16] have noticed the identical strength performance concerning Fly ash activated with this option to commercial Sodium Silicate, made by dissolving the WG through heating [6]. Ultimately, by taking $10 \mathrm{M} \mathrm{KOH}$ solution as an activator, the WG obtained strength roughly of $50 \mathrm{MPa}$, which is a smaller value than that of the $\mathrm{Na}+$ ion-containing system. Since the $\mathrm{K}+$ cation dissolves less of the $\mathrm{Ca}$ and $\mathrm{Mg}$ present in the preliminary material, a reduced amount of reaction yield precipitates $[18,19]$.

Lin et al., [20] have investigated the setting time of WG incorporated Metakaolin-based Geopolymers and recorded that the setting time experiment was employed to investigate the early and final fresh paste setting times. The early setting time displayed that the fresh paste lost the workability, and the final setting time pointed out that mechanical strength enhanced. Fig. 4 illustrate the setting time experiment outcomes. 


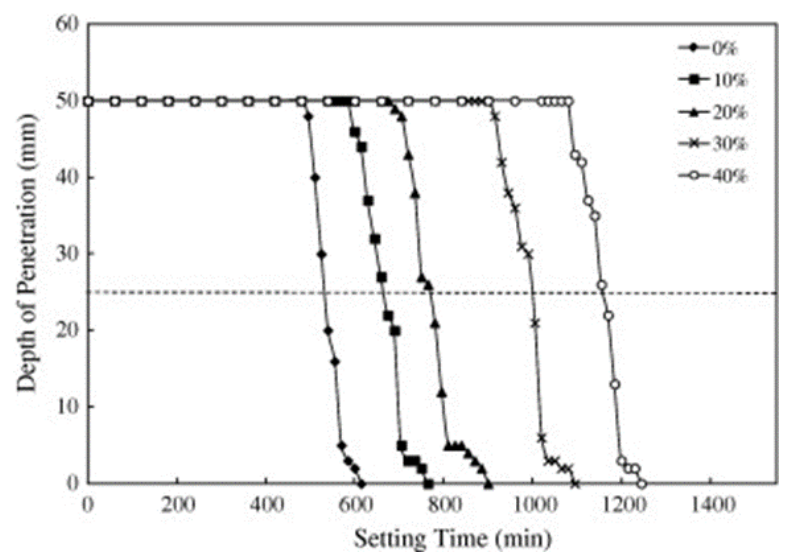

Fig. 4 Setting times of waste-glass metakaolin-based geopolymers [20]

Fig. 4 depicts that the setting time ascended as the Metakaolin (MK) was substituted with WG of TFT-LCD. The early and final setting times of the MK-based Geopolymers were around 533 min. and 615 min., correspondingly. Since more MK was substituted with WG of TFT-LCD, the early and final setting times are augmented. When $10 \%$ of the MK was substituted by WG of TFT-LCD, the early and final setting times were about $666 \mathrm{~min}$. and 765 min., in that order. While $40 \%$ of MK was substituted with WG of TFT-LCD, the early and final setting times boosted to $1158 \mathrm{~min}$ and $1245 \mathrm{~min}$ correspondingly. The upshots are represented that the Valorization WG of TFT-LCD enhanced the workability.

\subsection{Compressive Strength}

The study by Torres-Carrasco and Puertas [14], unearthed that the nature of the activator has affected significantly. Kastiukas and Zhou, [21] studied the influence of WG addition on the mechanical performance of Geopolymer binders accompanied by Tungsten Mining Wastes (TMW). The average compressive strength of the four poles apart compositions of Geopolymer binders with the substitution of TMW by WG for up to $40 \%$ by weight is summed up in Fig. 5.

The upshots achieved for only TMW-Geopolymer binders are also taken into account. Fig. 5 has pointed out that the compressive strength boosted with an enhancement of WG content across all ages. Substitution of $40 \%$ by weight of WG, i.e., specimens 60TMW40WG, have shown $16 \%$ of augment in $\mathrm{SiO}_{2}$ molar content and demonstrated the highest $28^{\text {th }}$ day compressive strength of $41 \mathrm{MPa}$; a $127 \%$ enhancement comparative to the $100 \mathrm{TMW}$ control specimen. The compressive strength at the initial age was also monitored to enhance with the boost in WG content. Commencing with the control specimen of $100 \mathrm{TMW}$, the compressive strength on the first day is merely $12.3 \%$ of the final 28 th-day strength.

Nevertheless, for 20,30 , and $40 \%$ substitution of TMW by weight with WG, the first-day strength enhances to $48.6,67.8$, and $72 \%$ of the ultimate 28 th-day strength. To investigate the latter strength enhancements, SEM micrographs of Geopolymer binders unearthing the micro-structural divergences in specimens manufactured incorporating WG are depicted in Fig. 6. 


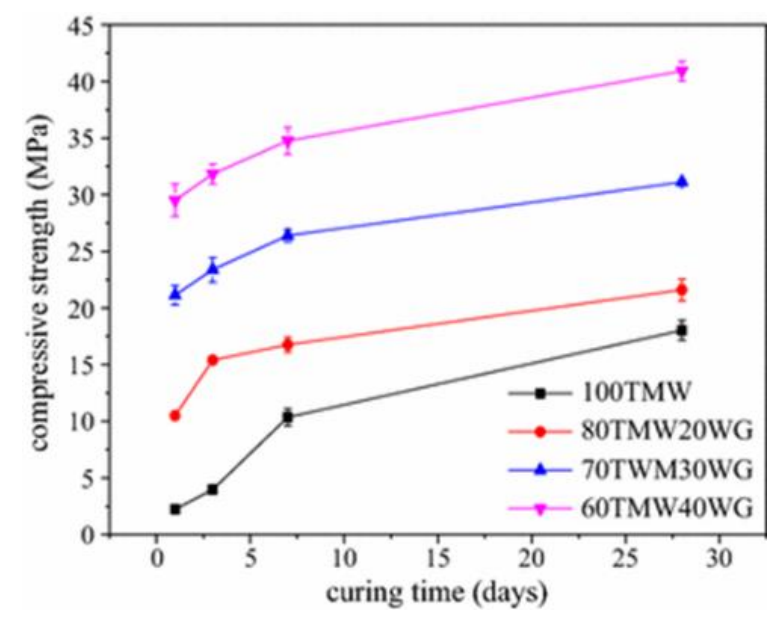

Fig. 5 Effects of WG on compressive strength [21]
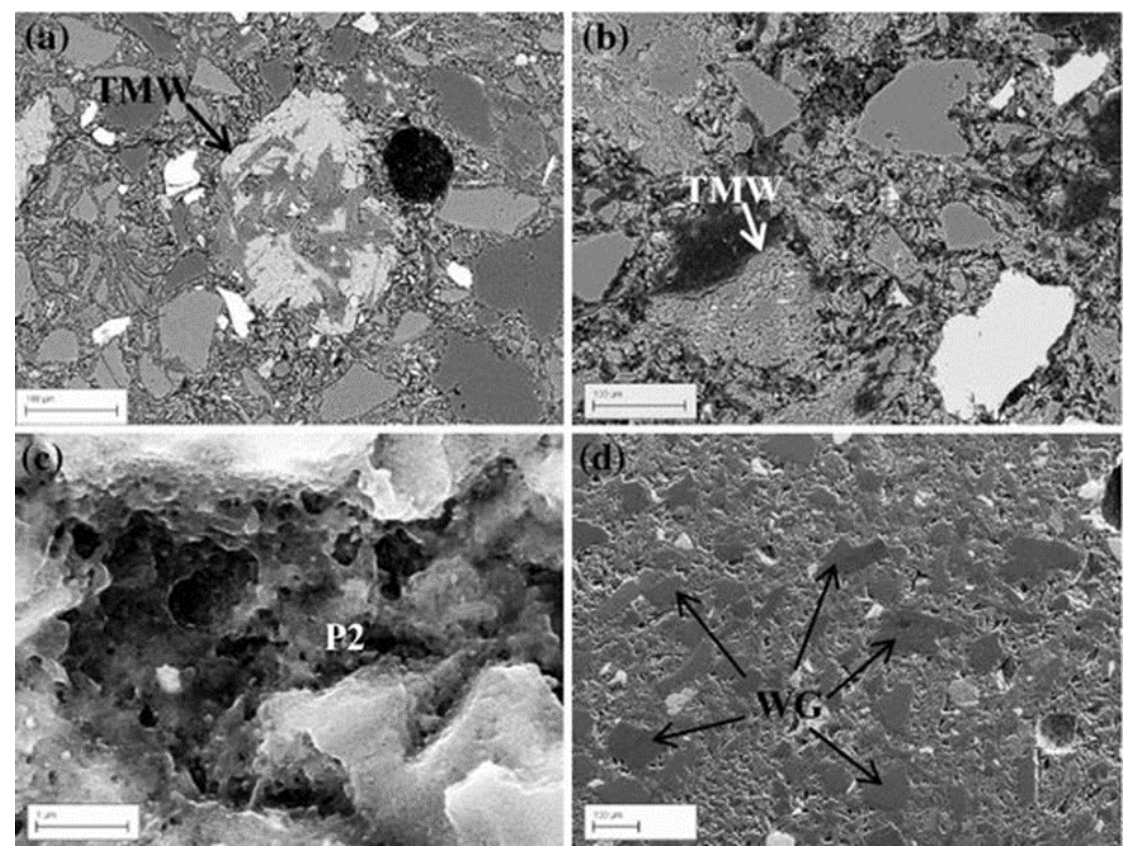

Fig. 6 SEM images of a 60TMW40WG, b 100TMW, c amorphous reaction products in 60TMW40WG and d unreacted WG particles [21]

Particles of TMW on the first day (60TMW40WG specimen) (Fig. 6a) displayed more zones of the Muscovite crystal with a laminated structure, which is shown as lighter areas that can be deduced as an augment in the echelon of $\mathrm{Al}$ and Si leaching. On the other side, the particles of Muscovite on the first day 100TMW specimens (Fig. 6b) stayed comparatively unaffected. The structure of specimens of 60TMW:40WG seems to have a smaller number of voids, whereas the reaction products emerge as denser and with more permanence, i.e., they are not composed of remote areas such as the case of 100TMWspecimens. 
Dense amorphous gel formations were also observed in the 60TMW:40WG as illustrated in Fig. 6c). Also, fig. demonstrates how WG particles are partly converting into amorphous reaction yields propping up the suggestion that an enlarged substitution of WG contributes a means of escalating reactive Silica and, in this manner, growing the Si: Al ratio. In other words, less dependence on employing more expensive and less sustainable soluble Silica met within commercial $\mathrm{Na}_{2} \mathrm{SiO}_{3}$ (Sodium Silicate) solution. Subsequent to 28 days, a lot of bulky particles of $\mathrm{SiO}_{2}$ were found entrenched in the matrix of Geopolymer binders as given away in Fig. 6d.

Nevertheless, it was not easy to establish the amount which came from the TMW and WG. However, it can be concluded that the enhanced WG content might not have merely contributed reactive Silica to the mixture but also encouraged to strengthen the Geopolymer binders as inert filler, most probably by the coarser portion of WG. The compressive strength results with the optimum substitution by WG, i.e., $40 \%$ by weight are comparable with the outcomes of Pacheco- Torgal et al.[22], who achieved 39.6 MPa at 28 days for TMW incorporated Geopolymer mortar. Though, the achievement was only subsequent to an energy-intensive Calcination of the TMW at $950^{\circ} \mathrm{C}$ for 2 hours.

A study by Rivera et al., [23] leads to the upshots of the compressive strength examinations on the synthesized Alkaline cement cured for 7 days, which are illustrated in Fig. 7. Even though the composition of the WG is extremely analogous, the compressive strength at 7 days, for the three alkaline-activated residues is very dissimilar.

The bottle residues represented the greatest resistance of $56 \mathrm{MPa}$ at low concentrations of the activator solution $\mathrm{NaOH}$ which was only 4 molar. The lower percentage of $\mathrm{NaOH}$ necessitated for the activation of the residue is not only cost-effective but also environmentally benign. This is attributed to the enhanced percentage of dissolution in alkaline condition, which is an index of the better reactivity, irrespective of the bulky size of the particle as the action of the medium could take place on the surface of the particles which stay entrenched in the alkaline activated matrix performing as a reinforcement that limits the propagation of cracks and augments the resistance. It has been chronicled that an elevated concentration of $\mathrm{MOH}$ activator where, $\mathrm{M}=\mathrm{Na}+$ or $\mathrm{K}+$ generates a high $\mathrm{pH}$ in the liquid phase, and results in an enhanced percentage of ionic species, that limits the mobility of ions and therefore, hinders the process of polymerization $[24,25]$.

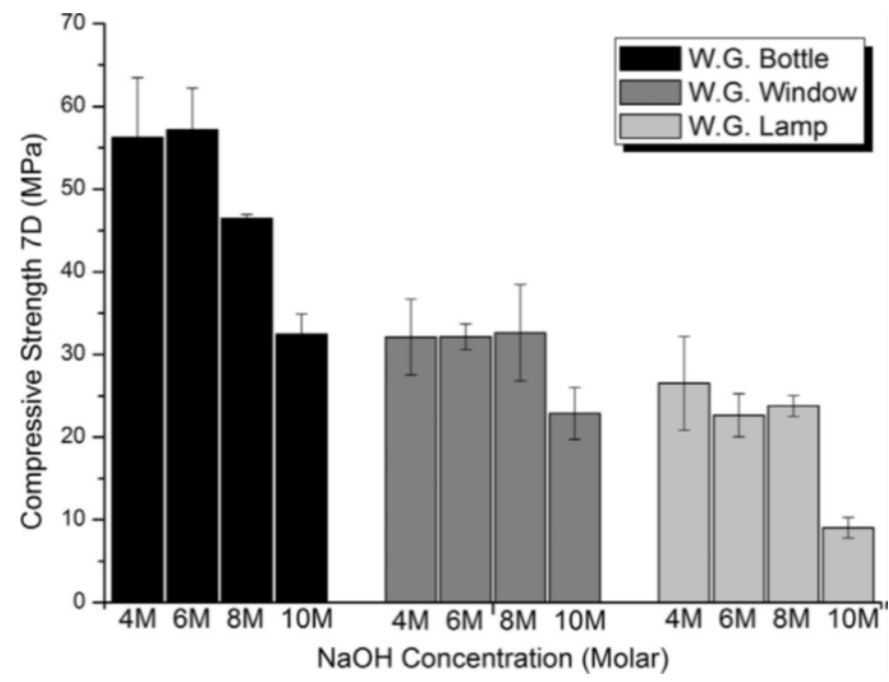

Fig. 7 Effect of waste glass (W.G) on Compressive strength at 7 days[23] 
What's more, Silica from the WG has a better solubility at higher concentrations of $\mathrm{NaOH}$ and at the reaction temperature which was $70^{\circ} \mathrm{C}$, extended its amorphous nature, and this surplus of soluble Silica in the mix is predicted to augment the viscosity of the network [26], by this means declining the mobility of Silicate chains in the formulation and providing to the loss of mechanical strength in the trial piece. A few researchers assigned this dwindle to an advanced attack on particles of WG by the alkali, which forms an outside layer on the particles which delays the reaction $[27,28]$. The said outcomes put forward the survival of a restricting value of the concentration of $\mathrm{NaOH}$, in particular, taking into account the contribution of Sodium from the WG.

The study of Rivera et al., [22] has obtained the value as 4 Molar, keeping the compressive strength almost constant or drop off considerably, as shown in Fig. 7. The referred result coincides with that recorded by Pascual et al. [27].

Fig. 8, the upshots of compressive strength of the Geopolymer samples employing $\mathrm{NaOH}$ of $4 \mathrm{M}$ as an activator are compared, at the ages of 7 and 28 days of curing. A drop in the context of the mechanical resistance at 28 days is monitored, of about $4 \%$ for bottle glass waste, $8 \%$ for window glass waste, and $32 \%$ for lamp glass waste. The falls in strength noticed between 7 and 28 days could be owing to the phase modifications taking place for the duration of ageing, though, shrinkage and cracking [26].

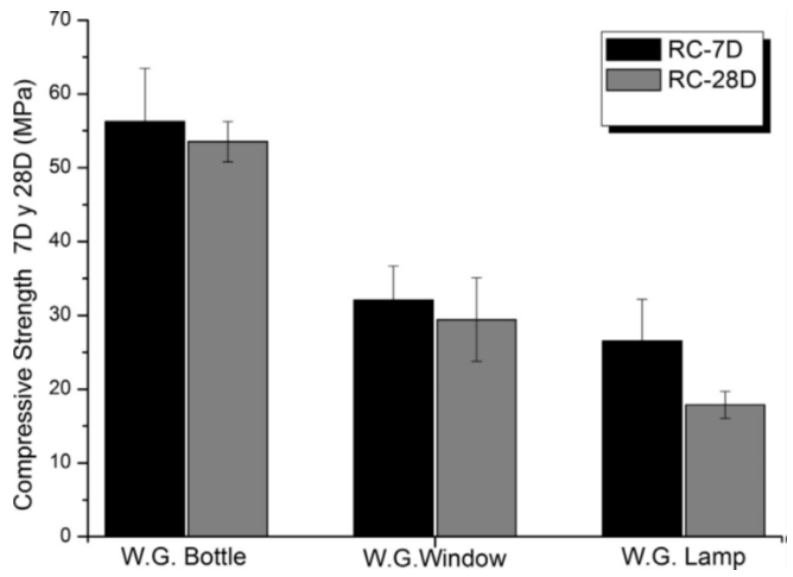

Fig. 8 Effect of waste glass (W.G) on Compressive strength at 7 and 28 days [23]

Haji Mohammadi et al. [28] have reported on the behavior of drying shrinkage of the Geopolymer pastes over time, which is demonstrated in Fig. 9. The control group with no aggregates possess the uppermost rate of shrinkage, which is supposed owing to the higher quantity of gel production for the analogous amount of binder paste as there are no aggregates present. The aggregates do not shrink, and hence influences the ultimate percentage of shrinkage of the system. Consequently, the quantity of aggregate content is significant for a reduction in shrinkage [29]. The Sand group displays a noticeably high proportion of shrinkage than the glass grouping. Mortars are well-known to exhibit low shrinkage in comparison with the pure paste, on account of the enclosing aggregates [30]. It is also identified that the size enhances of aggregates accelerates the drying shrinkage of the mortars [30,31].

For that reason, the behavior monitored in Fig. 9 is logical i.e., a decline in shrinkage from the control grouping to the Sand group and a further fall in shrinkage from the sand group to the glass group having finer WG particles. It is quite attention-grabbing to make a note that the glass group designates amazingly low shrinkage on the $7^{\text {th }}$ day and $14^{\text {th }}$ day; 
however, the shrinkage out of the blue quadruples on the 21st day! It stems from the fact that the WG-fine is fundamentally pozzolanic, and it will ultimately play a role in the kinetics of the Geopolymerization process. The quantity percentage of Silica dissolution from WG at ambient temperature is identified to be trifling [32].

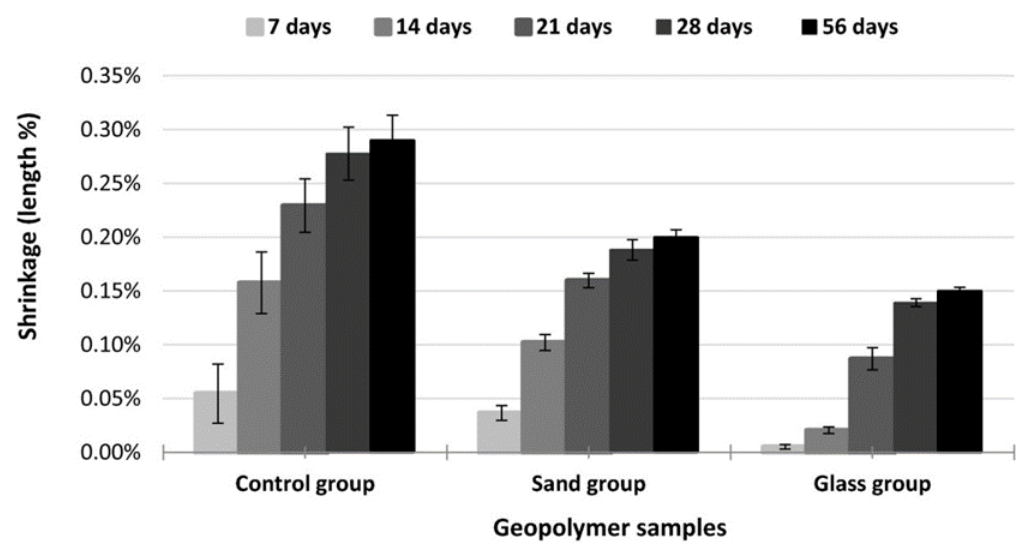

Fig. 9Drying shrinkage of geopolymer binders [28]

Also, another study by Puertas and Torres-Carrasco [33], has flashed lights on the mechanical performance of the pastes, which is depicted in Fig. 10. Fig. exhibits that compressive strength ascended with curing time in every one of the pastes. The least values of strength were noted down, at all ages, for paste Slag-Geopolymer with $\mathrm{NaOH} / \mathrm{Na}_{2} \mathrm{CO}_{3} . \mathrm{N} / \mathrm{C}$, i.e., the paste made with $\mathrm{NaOH} / \mathrm{Na}_{2} \mathrm{CO}_{3}$ as the activator, and the highest for a paste of slag Geopolymer with water glass solution, manufactured with water glass activator. The graph also displays that the greater the content of WG in the activator solution in the Slag-Geopolymer N/C family of pastes, the superior was their mechanical strength, though neither was as strong as a paste of WG-Slag Geopolymer. In the range of 100-0.01 $\mu \mathrm{m}$, the total porosity and pore size distribution for the pastes are correspondingly made known in Fig. 11, whereby the porosity values are demonstrated in the percentage of the entire specimen volume. The total porosity was highest in the paste of Slag-Geopolymer prepared with N/Cat all ages, varying from 18 to $24 \%$. While in the case of pastes made with Si possessing activators, total porosity was considerably low: 4 to $9 \%$ in WG-Slag Geopolymer and 7 to $9 \%$ in paste Slag Geopolymer made with N/C-25. Pore size distribution pursued an analogous pattern as shown in Fig.11, with a higher proportion of micro and mesopores in the pastes manufactured with the silicon-activators. The paste made with $25 \mathrm{~g} / 100 \mathrm{~mL}$ WG had a bigger fraction of pores lesser than $0.01 \mu \mathrm{m}$. These total porosity and pore size distribution outcomes are constant with the compressive strength obtained for the materials examined, as demonstrated in Fig. 10. 


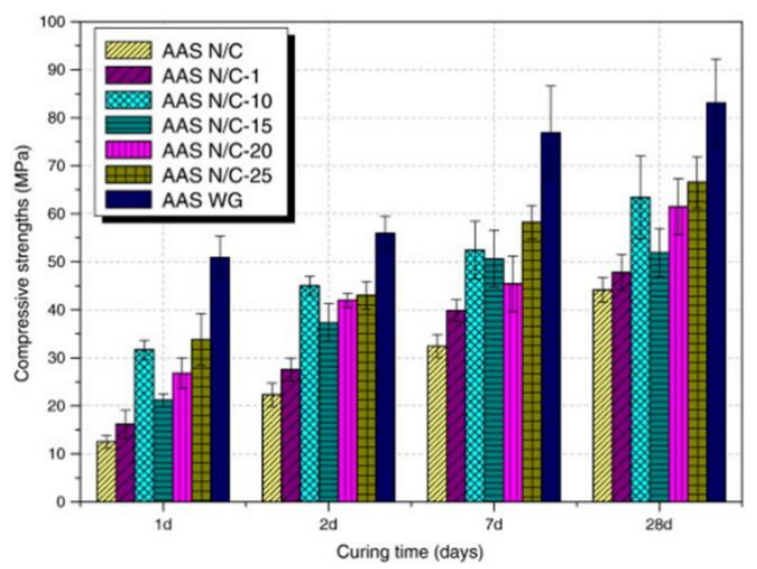

Fig. 10 Compressive strength of AAS pastes [11]

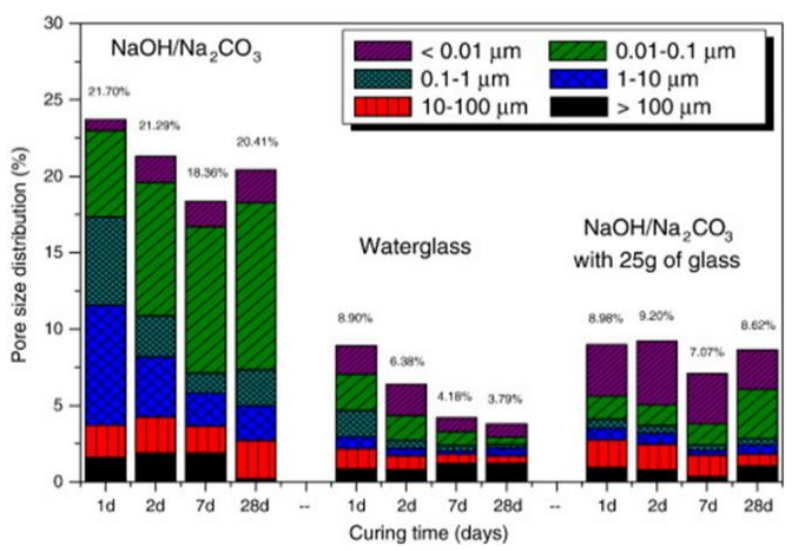

Fig. 11 Pore size distribution in pastes [33]

Martinez-Lopez and Escalante-Garcia, [34] have also studied concerning the compressive strength of the Geopolymer paste evolution from 1 to 28 days for the pastes grouped by the quantity percentage of WG. The compressive strength generally enhanced with the period, and the greatest strength at 28 days was for specimen CN1 with $4 \% \mathrm{Na}_{2} \mathrm{O}$ employing $\mathrm{NaOH}$ as an activator, $0 \% \mathrm{WG}$, and curing at $20^{\circ} \mathrm{C}$. Paste $\mathrm{CN} 17$ demonstrated a strength reduce following 14 days owing to the long-termed curing at a higher temperature, following Puertas [35], who talked about the strength decline that it is owing to the slimming down of Silica gel phase developed at early ages, Silica gel encloses water not bound chemically and it evaporates readily at elevated temperature, this reduction results into formation of cracks in strength detriment. It is discernible that in trials of 0 to $25 \%$ WG, i.e., with a low percentage of WG, the strength mitigated with the boost of percentage quantity of $\mathrm{Na}_{2} \mathrm{O}$; the enhance of $\mathrm{Na}_{2} \mathrm{O}$ contents in blast furnace slag (BFS) has been recorded to trim down the strength [36,37].

Wang [38]designated that 2 to $8 \%$ of $\mathrm{Na}_{2} \mathrm{O}$ was enough to acquire higher strength in BFS pastes, some other researchers have also signified that a surplus of Alkalis directed to Carbonation and strength loses owing to the referred phenomenon[37,39].On the other side, the pastes with $50 \%$ WG demonstrated inferior strength for 4 to $8 \%$ of $\mathrm{Na}_{2} \mathrm{O}$ that points that the Slag and class contested for an inadequate quantity of activator, it also 
seems that the strength enhanced with a grouping of elevated curing temperature, enhanced quantity percentage of $\mathrm{Na}_{2} \mathrm{O}$ along with the presence of $\mathrm{Na}_{2} \mathrm{CO}_{3}$; however, the on the whole attitude of these composites designate that there was no apposite percentage of content of $\mathrm{Na}_{2} \mathrm{O}$, i.e., lower content of $\mathrm{Na}_{2} \mathrm{O}$, were not as much as essential for the activation of WG, and a high percentage of $\mathrm{Na}_{2} \mathrm{O}$ had a pessimistic impact on the activation of BFS, as reported in the micro-structures as shown in Fig. 12, whereby the quantity of non-reacted WG particles was elevated in comparison with other trials. It was accounted that the advanced percentage of WG advantaged from the amalgamation of $\mathrm{Na} 2 \mathrm{CO} 3$, as demonstrated by trials CN6, CN15, CN17, and CN25 with 25\%, 50\%, 75\%, and $100 \%$ of WG respectively.

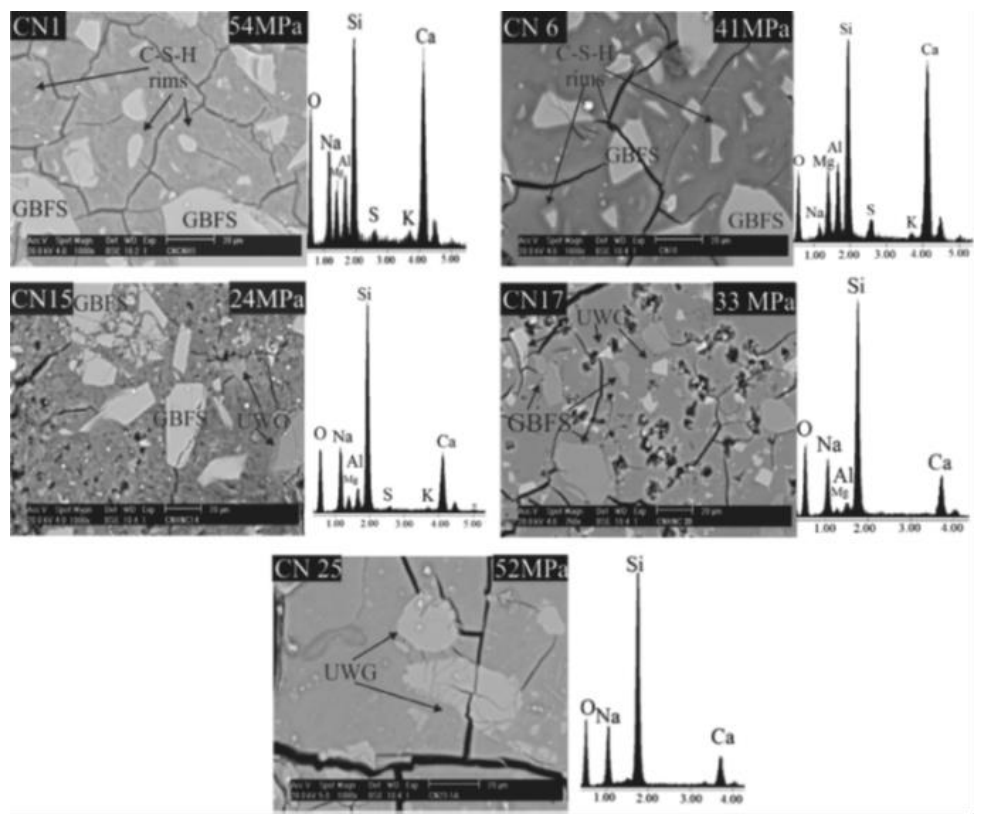

Fig. 12 Scanning electron micrograph of the samples CN1, CN6, CN15, CN17 and CN25 at 28 days [34]

Ruiz-Santaquiera [40] found that the solubility of glass was found more employing an activation solution of $\mathrm{NaOH}: \mathrm{Na}_{2} \mathrm{CO}_{3}$ at the ratio of 50:50, and Sodium Carbonate functions as a pH stabilizer in Alkaline solution; i.e., for merely $\mathrm{NaOH}$, the Ions of Hydroxide [OH] declined as the Silica dissolved, on making the adding together of $\mathrm{Na}_{2} \mathrm{CO}_{3}$ permitted the $\mathrm{OH}$ - ions to stay quite constant with time, permitting the split of more Si AO bonds. The temperature for curing also had a powerful impact on strength; elevated temperatures supported the early strength; this was in harmony with accounts on BFS binders [41-43]. The author also mentioned the WG necessitates a prolonged curing time to build up higher mechanical characteristics.

Tho-In et al., [44] 'What's more to add, the compressive strengths of the Fly Ash based Geopolymer pastes with diverging substitutions of Fly Ash by WG. The upshots fingers towards the substitution levels of both fluorescent lamp glass powder (FP) and ground container glass powder (CP) have imperative impacts on the compressive strengths of Geopolymer pastes. The best possible performances for FP and CP substitutions are attained from the 10FP and 20CP samples with compressive strengths of $41.1 \mathrm{MPa}$ and 47.6 $\mathrm{MPa}$, correspondingly, whereas the reference paste displays a compressive strength of 45.7 MPa. With substitution by FP, the compressive strength inclines to reduce as the 
substitution level is enhanced. Samples 10FP,20FP, 30FP and 40FP demonstrate compressive strengths of $41.1,40.7,39.6$, and $33.3 \mathrm{MPa}$, in that order, while $100 \mathrm{FA}$ has a compressive strength of $45.7 \mathrm{MPa}$. The decline in compressive strength may be assigned to the substitution with FP, altering the Silicon: Aluminum ratio on account of its elevated Silicon content. The attributes of Geopolymers are considerably modified with comparatively little alterations in Silicon and Aluminum contents during the Geopolymerization of Alumino-Silicates [45]. Higher Silicon: Aluminum ratios persuade the development of low cross-linked Alumino-Silicate materials with reduced strengths[46, 47].

Davidovits [48], as well as Chindaprasirt et al. [49], have pointed out that the optimum Silicon: Aluminum ratio for a good-strength Geopolymer was among 3.5 to 4.0. Nevertheless, the geopolymer samples employing 10 to 30\%FPdemonstrated compressive strengths of 87 to $90 \%$ that of the reference paste owing to the higher fineness of the FPparticles. The fine FP- particles play the role of micro-fillers for the Geopolymer paste, inducing matrix densification. The compressive strengths of Geopolymer paste incorporating CP are also mitigated, analogous to those amalgamating FP, on account of the enhanced Silicon: Aluminum ratios. Nevertheless, the compressive strengths of the CPpastes are superior to FP-pastes at the constant substitution levels. This is for the reason that the $\mathrm{CaO}$ content of $12.80 \%$ in $\mathrm{CP}$ is greater than in $\mathrm{FP}$, which was $7.43 \%$. High $\mathrm{CaO}$ levels in Geopolymer pastes have been accounted to form supplementary Calcium-SilicateHydrate or Calcium Alumino-Silicate Hydrate phases along with other Geopolymerization yields, consequently, producing denser structures and enhanced strengths [50,51]. The Geopolymer paste is incorporating $20 \% \mathrm{CP}$ demonstrates the greatest compressive strength of $47.6 \mathrm{MPa}$, a little more than that of the reference paste. This may be due to the amalgamation of a correct quantity of fine CP-particles with a higher content of $\mathrm{CaO}$.

\subsection{Thermal}

Badanoiu et al. [52], have examined thermal attributes in the context of mass changes, porosity, and compressive strength. They reported that the mass alterations evaluated on the cubic paste samples treated at diverse temperatures are represented in Fig. 13.

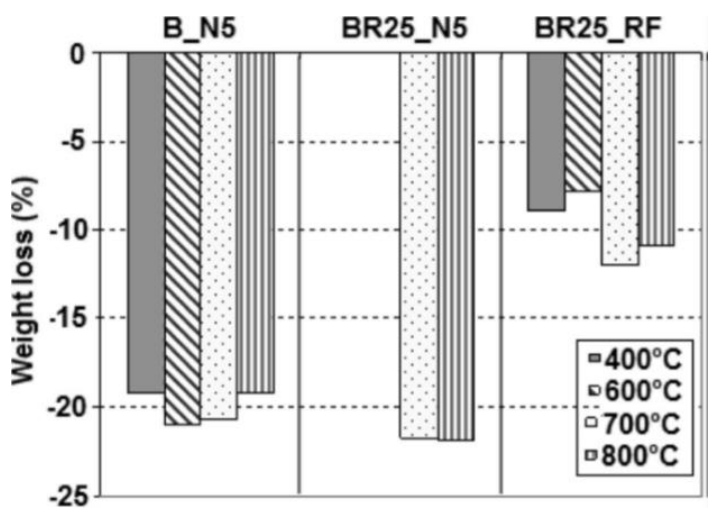

Fig. 13 Mass loss of pastes after thermal treatment at different temperatures [52] 
The mass losses noted down for B_N5 ( $\mathrm{NaOH} 5 \mathrm{M}$ ), and BR25_N5 (NaOH $5 \mathrm{M}$ ) pastes subsequent to thermal treatment at temperatures among 400 and $800^{\circ} \mathrm{C}$ is consisted among $19 \%$ and $22 \%$; this significant weight loss is chiefly owing to the dehydration and transformation of Sodium Silicate (Aluminate) Hydrates which confirms the foaming of the material. For theBR25_RF (Red mud slurry filtrate (RF) pastes, the mass losses are smaller with 8 to $12 \%$ mostly owing to the low-quantity of Sodium Silicate (Aluminate)Hydrates developed when filtrate $\mathrm{RF}$ with low alkalinity in comparison with $\mathrm{NaOH} 5 \mathrm{M}$ was employed as the liquid ingredient. Two B_N5 pastes - one treated at $600^{\circ} \mathrm{C}$ and another at $800^{\circ} \mathrm{C}$, possess the apparent density values smaller than $0.866 \mathrm{~g} / \mathrm{cm}^{3}$. For theBR25_N5 pastes, apparent density the values trim down with the augment of temperature for thermal treatment. The said data are in good agreement with the enhancement of open porosity, which also evaluated visually as depicted in Fig. 17. The greatest values for open porosities are documented for BR25_RF paste prior to and subsequent to thermal treatment at $400^{\circ} \mathrm{Cand} 600^{\circ} \mathrm{C}$. The referred values can be compared with the loose and heterogeneous micro-structure specific for the said samples, as exemplified in Figs. 14, 15, and 16 . Thermal treatment at $700^{\circ} \mathrm{C}$, which is exceeding the melting point of brown glass, confirms paste reduction and densification of the micro-structure as portrayed in Fig.-18 in comparison with Fig.-15c and 15d.

As a result, the open porosity sharply declines to $1.64 \%$. The enhancement in temperature for thermal treatment to $800{ }^{\circ} \mathrm{C}$ trims down the viscosity of the melt stage, and the gases generated by Sodium Silicate(Aluminate, Ferrite) stages develop bubbles in the material; thus, the micro-structure represents abundant pores of a variety of sizes Fig. $19 \mathrm{e}$ and 19f, and the open porosity value enhances again. Fig. 19 illustrates the evolution of verses temperature values of compressive strength. ForB_N5 paste, the values of the compressive strength declines with the escalation of thermal treatment temperature, in fine correlation with the augment of porosity. Even so, the compressive strength of 2 to 5 $\mathrm{MPa}$ is fine for foamed materials [53]. Densification of the micro-structure of BR25_RF paste treated at $700^{\circ} \mathrm{C}$ confirms an imperative augment of compressive strength, which is found at $25 \mathrm{MPa}$. Expectedly, the enhancement of open porosity, for pastes treated at $800^{\circ}$ Cdetermines to dwindle in compressive strength, but the value found of $8.6 \mathrm{MPa}$ is still higher. 


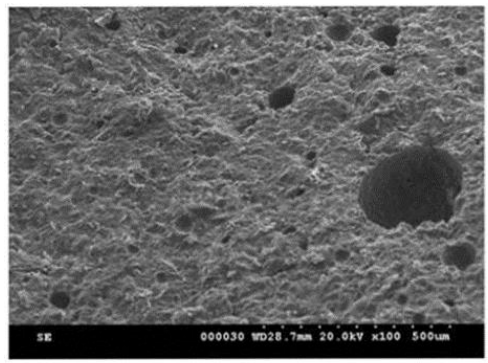

a

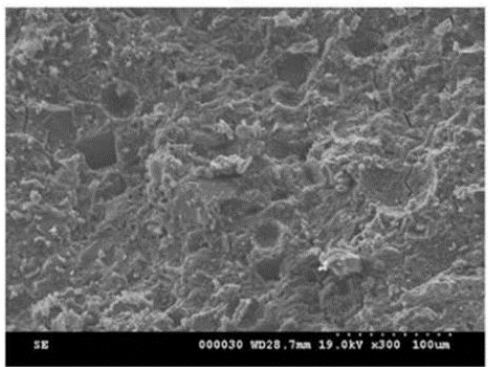

c

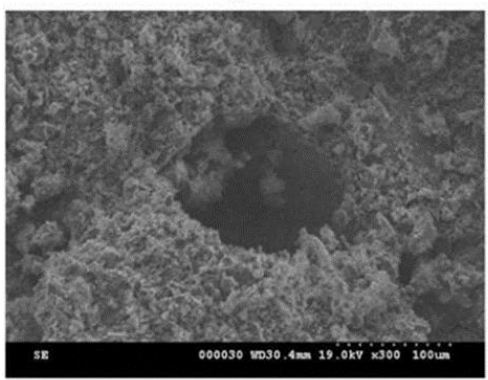

e

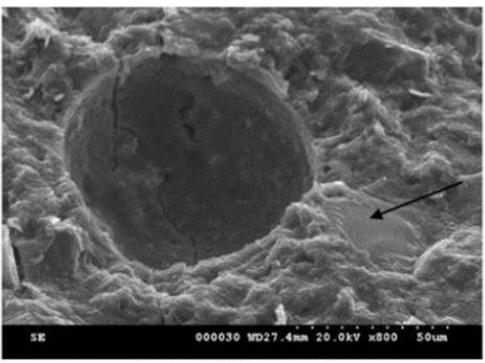

b

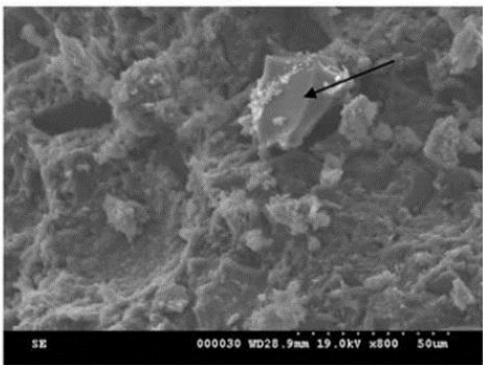

d

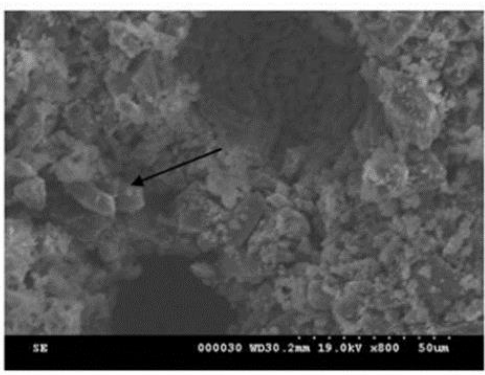

f

Fig. 14 SEM micrographs of B_N5 (a and b), BR25_N5 (c and d), and BR25_RF (e and f) paste before thermal treatment [52]

Zhang et al., [54] have clarified that as an ingredient in Geopolymer concrete the surface of the WG-aggregates can react with Alkaline solution over time and good binding with the Geopolymer paste in bulk. Furthermore, the development of compressive strength of paste mixes with escalating waste glass powder (GP) as powder coal fly ash (PCFA) substitution from $0 \%$ to $30 \%$ is displayed in Fig. 21. 


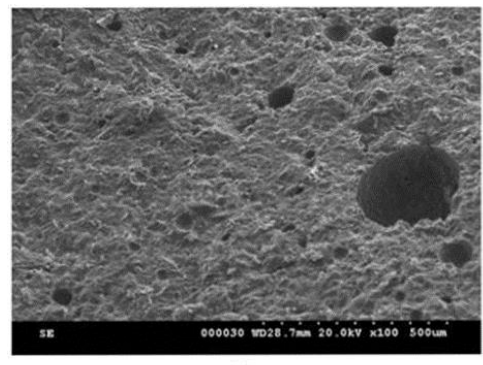

a

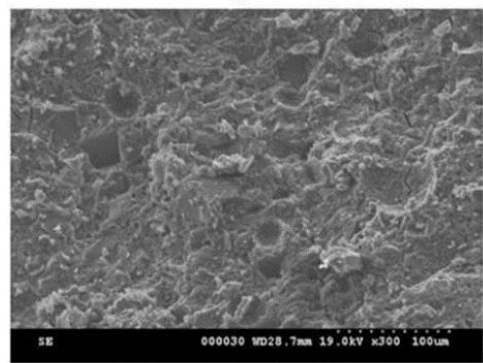

c

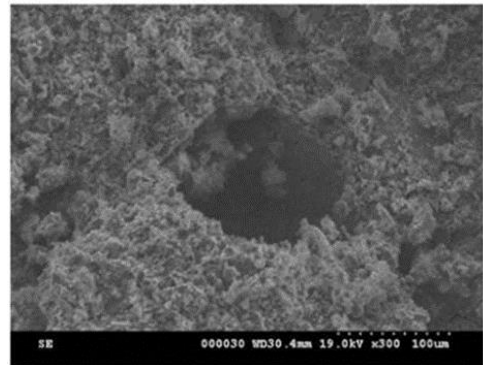

e

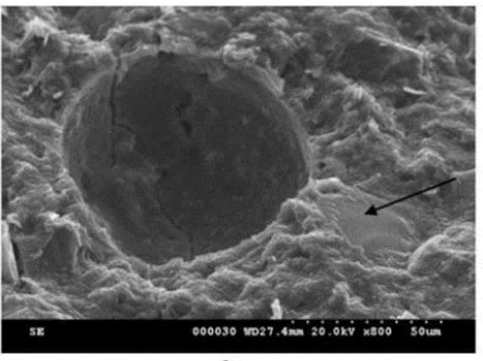

b

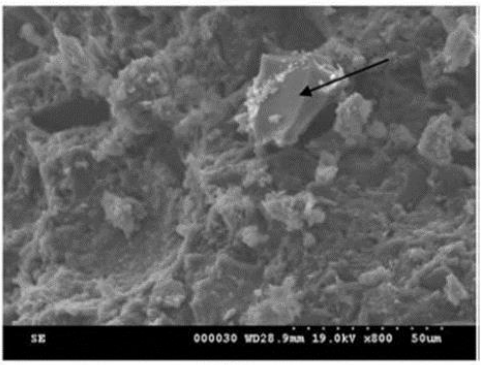

d

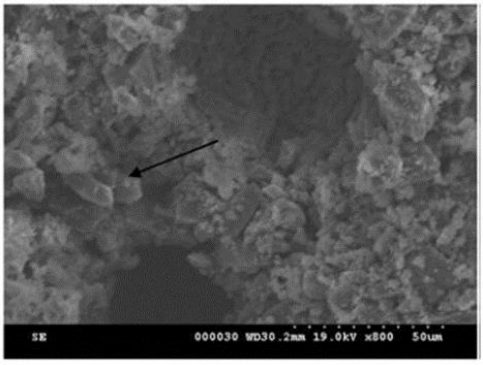

f

Fig. 15 SEM micrographs of B_N5 (a and b), BR25_N5 (c and d) and BR25_RF (e and f) paste after thermal treatment at $400^{\circ} \mathrm{C}$ for $1 \mathrm{~h} \mathrm{[52]}$ 


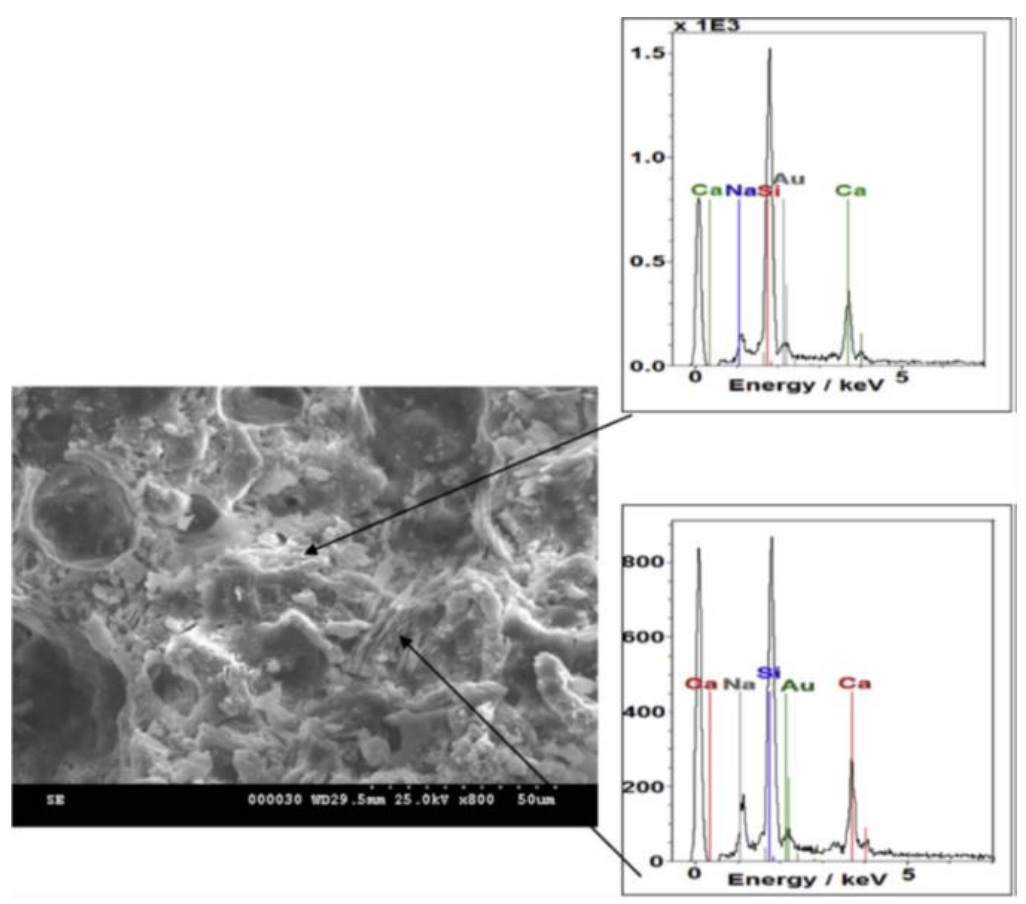

Fig. 16 SEM micrograph and EDX analysis B_N5 paste treated at $400{ }^{\circ} \mathrm{C}$ for $1 \mathrm{~h}$ [52]

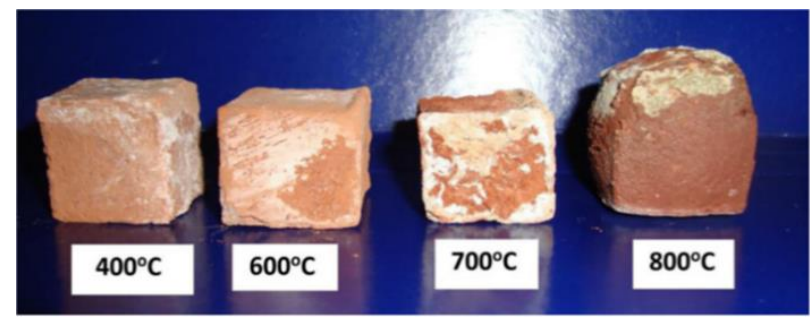

Fig. 17The visual aspect of BR25_RF pastes after thermal treatment for $1 \mathrm{~h}$ at temperatures between 400 and $800{ }^{\circ} \mathrm{C}$ [52]

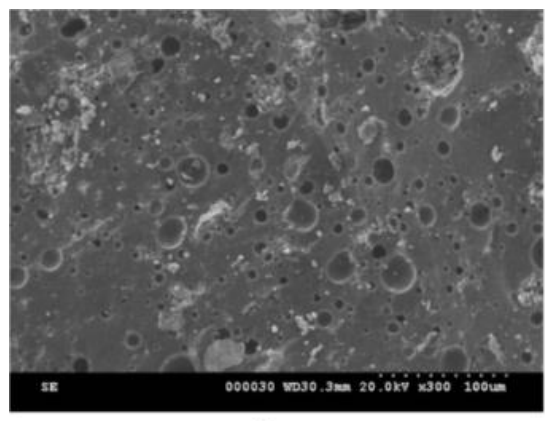

a

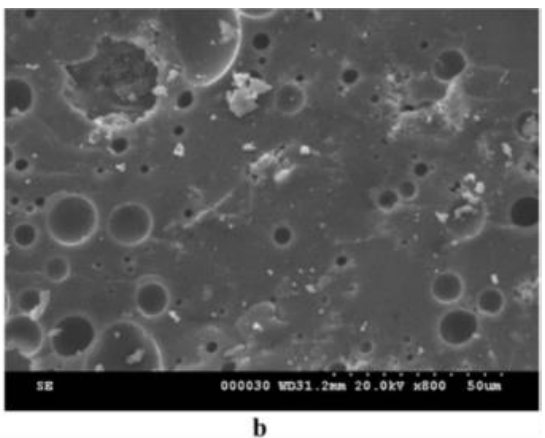

b

Fig. 18 SEM micrographs of BR25_RF paste after thermal treatment at $700{ }^{\circ} \mathrm{C}$ for $1 \mathrm{~h}$ [52] 


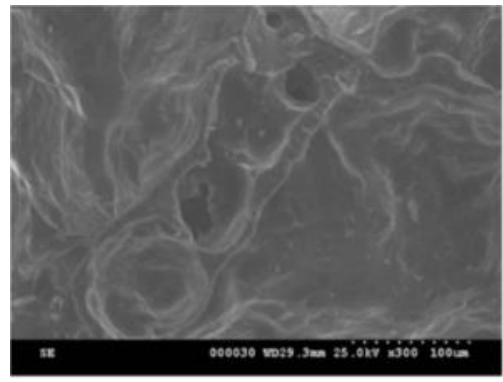

a

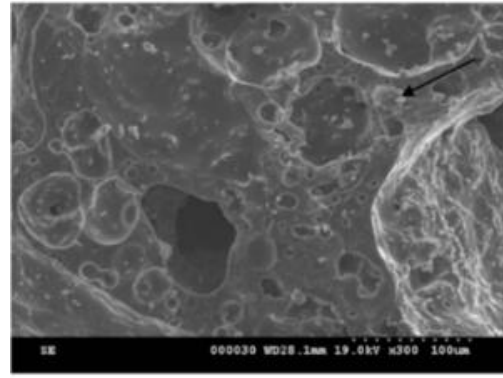

c

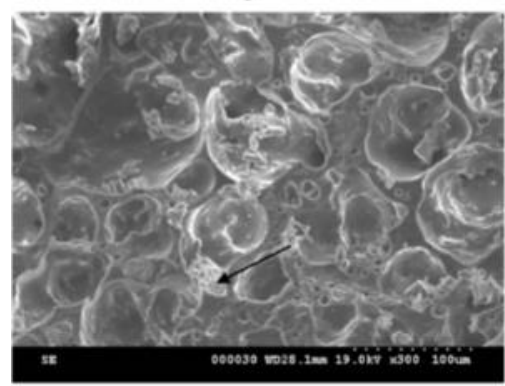

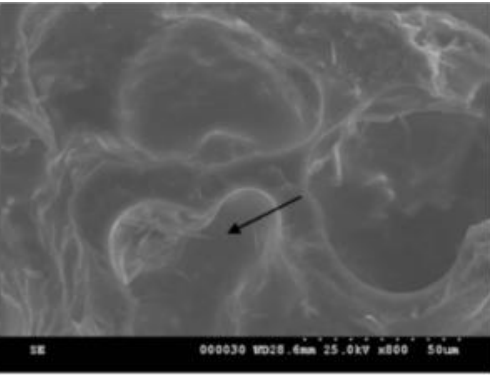

b

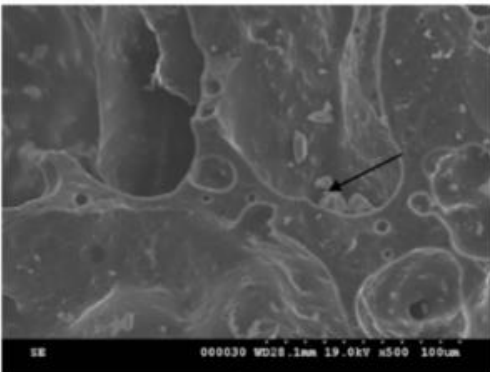

d

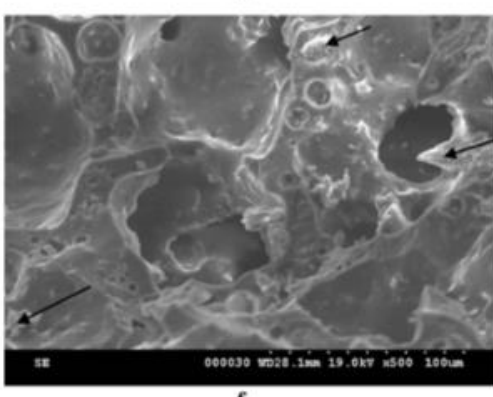

f

Fig. 19 SEM micrographs of B_N5 (a and b), BR25_N5 (c and d) and BR25_RF (e and f) paste after thermal treatment at $800^{\circ} \mathrm{C}$ for $1 \mathrm{~h}$ [52]

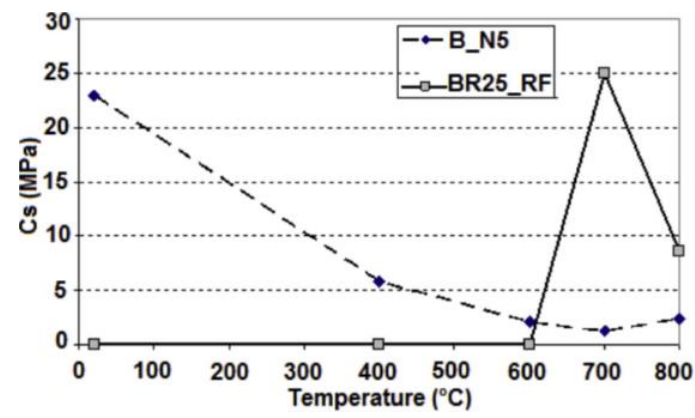

Fig. 20 Compressive strengths of pastes before and after thermal exposure [52] 


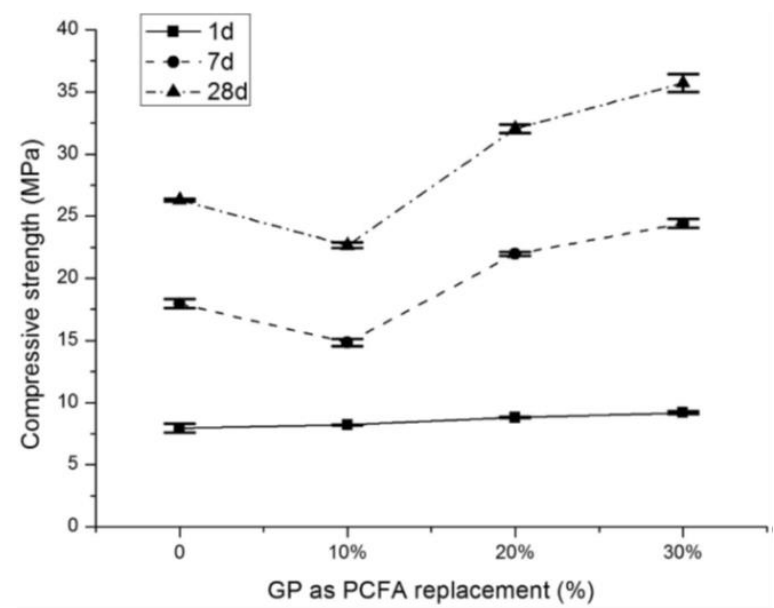

Fig. 21 Compressive strength development of paste with GP as PCFA [54]

The compressive strength of one day is identical within all mixes while the compressive strength accelerates considerably at 7 and 28 days with a greater quantity of GP substitution. In comparison with $\mathrm{R}$ [0\% substitution], up to $35 \%$ strength enhance is monitored in G30 [30\% GP as PCFA substitution]. The said augment could be assigned to the advanced GP reactivity and accessibility of soluble Silica contributed by the reaction among GP and $\mathrm{NaOH}$ that encourages the Geopolymerization procedure and directs to elevated quantity of gel development. The international activation course is comparable to the conjugational impact of employing Sodium Silicate and Sodium Hydroxide as alkali activator. Preceding investigations also determined that this conjugational impact consequences in supplementary accessible Silica in the system and escalates the gel Polycondensation [55], which provides improved mechanical attributes. More than that, Fly ash is well-known to possess Hollow Cenospheres and Plerospheres that are susceptible to surface opening within dissolution course of action. For that reason, the production of reaction yields is supposed to be stimulated on the internal PCFA surface [56,57]. This occurrence has also been determined in PCFA cement paste mixtures, where reacted hollow PCFA-particles offer additional room for the reaction yields [58]. The opening of the "'closed' voids in PCFA was investigated by alkaline solution treatment to validate that the PCFA in the study may also hold reaction yields. A comparison of the pore structure of with and without treated PCFA through $4 \mathrm{M} \mathrm{NaOH}$ solutions for 2 hours uncovers palpable disparities. As given away in Fig. 22 (a), the total porosity of the without treated original ash was $5.69 \%$ while it got enhanced to $17.42 \%$ subsequent to treatment.

Not only that, Fig. 22(b) designates that the pore size range expands from 3 to $6 \mu \mathrm{m}$ towards 2 to $10 \mu \mathrm{m}$ following treatment with an alkaline solution. Consequently, all the referred facts suggested that the surface opening of hollow PCFA may amplify the ease of access of the finer pores, and that's why endorse the reaction yields production within PCFA-particles.

Nevertheless, they inefficiently offer the bonding of particles that directs to reduce compressive strength. This impact inclines to be diluted on escalating the content of GP since the diminished potential for the PCFA to have room for reaction yields. For that reason, they are augmenting the quantity of GP, finally pilots to augmentation of the compressive strength. On the other hand, a substantial strength decline is met within the case of G10 10\% of GP in comparison to R at 7 and 28 days, which entails that dissimilar 
mechanisms are engaged at lower substitution levels. This unforeseen propensity may be induced by the finer size of the particle distribution of GP in comparison with PCFA.

(a)

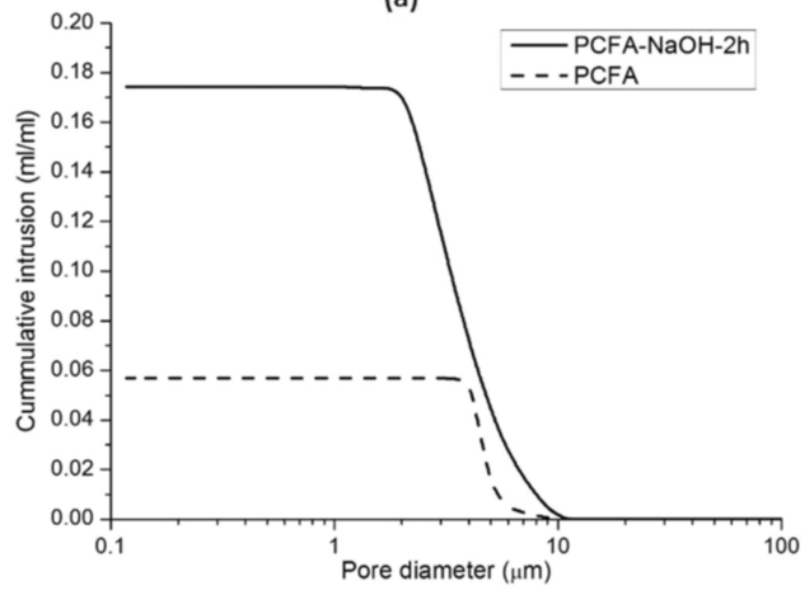

(b)

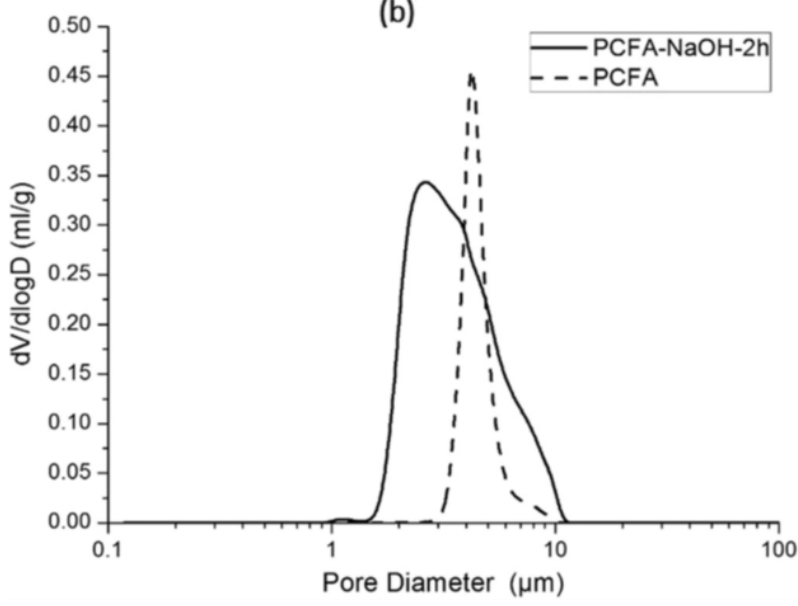

Fig. 22(a) cumulative pore-size distribution and (b) differential pore size distribution [54]

The diminutive size of a particle of GP and its angular shape may have a pessimistic effect on the stuffing density of the mix [59] that could escort to a compressive strength drop off. For the moment, the low density of mix with GP substitution may also contribute to the strength reduction. It is worthless that the impacts are merely predominant on the compressive strength development at low GP substitution levels [ $\leq 10 \%]$. With advanced GP substitution levels $[\geq 20 \%]$, the governing feature may progressively alter from the physical impact toa chemical one. Compared with R mix, merely a slight augment of gel development is found inG10whereas a noteworthy augment is monitored inG20 and G30 $(20 \%$, and $30 \%$ of GP) mixes. 


\subsection{Microstructural}

Kastiukas and Zhou [60] explored the impact of WG supplement of WG on microstructural attributes of Geopolymer binders incorporated with Tungsten Mining Wastes (TMW). The initial age reaction product development in the 100 TMW (100\% tungsten mining waste) specimens is publicized in Fig. 23a. The outcomes from the SEM imaging illustrate sites of $\mathrm{N}-\mathrm{A}-\mathrm{S}-\mathrm{H}$ gel reaction products, say $\mathrm{P} 1$, with dissimilar cation and anion replacement of $\mathrm{Fe}$, $\mathrm{Mg}$, and $\mathrm{K}$ that possess the structure of amorphous type and point up branch-like formulations bridging the reaction products collectively. The same reaction yields can also be observed integrating with the particles of Quartz from the TMW, developing the gel system. Fig. 23b encompasses crystals of Muscovite (M) into TMW incorporating Geopolymer binders is shown to form a thickly laminated structure for the duration of Alkali activation indicative of uptake of hydroxyl $(\mathrm{OH})$ ions on account of rehydroxylation. Through EDX micro-analyses, the Al: Si ratio for non-reacted Muscovite was confirmed as 1.0 when readings recorded subsequent to one day of reaction with the Alkali activator noticed the latter value plunge to 0.65 , representing an obvious signal of the discharge of Aluminium cations into the solution.

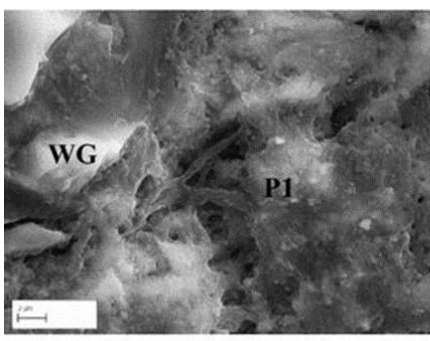

(a)

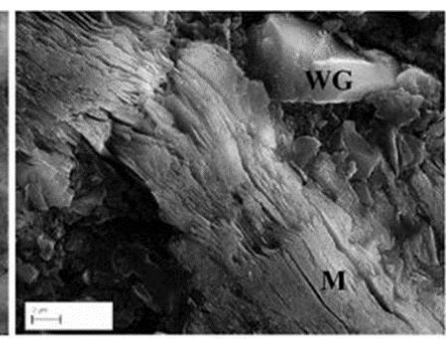

(b)

Fig. 23 SEM image of TMW incorporating geopolymer binder [60]

\section{Conclusion and discussion}

This paper reviews the valorization of the applications of WG incorporation for the development of geopolymer paste and discussed the previous few studies on workability, strength, thermal, and microstructural properties. This review included the possibility of employing WG in a geopolymer as a precursor for alkaline cement. The review reveals that it is wholly possible to blend these wastes in construction and building materials, sans any further makeover beyond crushing to develop innovative Geopolymer building materials. Geopolymer paste with a lightweight glass waste aggregate can be used as foam concrete. Glass can be ground easily to very fine particles that can replace fine sand in lightweight geopolymer foams. Over the time, the surface of the glass particles reacts with the paste and forms stronger bonds with the geopolymer binder. These inimitable features make glass fines a suitable substitute for fine sand in geopolymer foam applications. To sum up, the application of WG has been established as a valuable material in making Geopolymers with excellent and acceptable attributes that valorize it as an economical and sustainable construction material. This is a valuable step putting a step forward towards the "Green Concept" and in the direction of its valorization. 


\section{References}

[1] Luhar S, Cheng TW, Nicolaides D, Luhar I, Panias D, Sakkas K. Valorisation of glass wastes for the development of geopolymer composites - Durability, thermal and microstructural properties: A review. Construction and Building Materials 2019, 222, 673-687. https://doi.org/10.1016/j.conbuildmat.2019.06.169

[2] Luhar S, Cheng TW, Nicolaides D, Luhar I, Panias D, Sakkas K. Valorisation of glass waste for development of Geopolymer composites - Mechanical properties and rheological characteristics: A review. Construction and Building Materials 2019, 220, 547-564. https://doi.org/10.1016/j.conbuildmat.2019.06.041

[3] Shaikh FUA, Luhar S, Arel HŞ, Luhar I. Performance evaluation of Ultrahigh performance fibre reinforced concrete - A review. Construction and Building Materials 2020, 232. https://doi.org/10.1016/i.conbuildmat.2019.117152

[4] Luhar S, Cheng TW, Luhar I. Incorporation of natural waste from agricultural and aquacultural farming as supplementary materials with green concrete: A review. $\begin{array}{lllll}\text { Composites } & \text { Part } & \text { B: } & \text { Engineering }\end{array}$ https://doi.org/10.1016/i.compositesb.2019.107076

[5] Chao JY. Manufacturing and properties of alkali-activated waste glass cement (Master thesis). National Cheng Kung University, 2008.

[6] Luhar S, Chaudhary PS, Luhar I. Influence of Steel Crystal Powder on Performance of Recycled Aggregate Concrete. IOP Conference Series: Materials Science and Engineering 2018, 431. https://doi.org/10.1088/1757-899X/431/10/102003

[7] Luhar S, Dave UV, Chaudhary S. A Brief Review On Geopolymer Concrete. 5th Nirma University International Conference On Engineering, Ahmedabad, 2015.

[8] Luhar S, Dave U. Investigations On Mechanical Properties Of Fly Ash And Slag Based Geopolymer Concrete. Indian Concrete Journal 2016, 34-41.

[9] Luhar S, Chaudhary S. Effect Of Elevated Temperatures On Rubberized Geopolymer Mortar. International Journal Of Civil, Structural, Environmental And Infrastructure Engineering Research And Development 2016, 79-86.

[10] Luhar S. Fly, Ash And Slag Based Geopolymer Concrete: Experimental Facts. Lap Lambert Academic Publishing, 2016.

[11] Luhar S. Performance Evaluation Of Rubberized Geopolymer Concrete And Fly AshBased Geopolymer Mortar. (Thesis), 2018.

[12] Luhar S, Luhar I. Potential application of E-wastes in construction industry: A review. Construction and Building Materials 2019, 203, 222-240. https://doi.org/10.1016/j.conbuildmat.2019.01.080

[13] Wang WC, Chen BT, Wang HY, Chou HC. A study of the engineering properties of alkaliactivated waste glass material (AAWGM). Construction and Building Materials 2016, 112, 962-969. https://doi.org/10.1016/i.conbuildmat.2016.03.022

[14] Torres-Carrasco M, Puertas F. Waste glass as a precursor in alkaline activation: Chemical process and hydration products. Construction and Building Materials 2017, 139, 342-354. https://doi.org/10.1016/i.conbuildmat.2017.02.071

[15] Yang KH, Song JK. Workability Loss and Compressive Strength Development of Cementless Mortars Activated by Combination of Sodium Silicate and Sodium Hydroxide. Journal of Materials in Civil Engineering 2009, 21, 119-127. https://doi.org/10.1061/(ASCE)0899-1561(2009)21:3(119)

[16] Torres-Carrasco M, Puertas F. Waste glass in the geopolymer preparation. Mechanical and microstructural characterisation. Journal of Cleaner Production 2015, 90, 397-408. https://doi.org/10.1016/i.jclepro.2014.11.074

[17] Carrasco M, Puertas F. Sodium silicate solutions from dissolution of glass wastes. Statistical analysis. Materiales de Construcción 2014, 64 https://doi.org/10.3989/mc.2014.05213 
[18] Fernández-Jiménez, A.; Palomo, A.; Criado, M. Alkali activated fly ash binders. A comparative study between sodium and potassium activators. Materiales de Construccion 2006, 56, 51-65.

[19] Xu H, van Deventer JSJ. The effect of alkali metals on the formation of geopolymeric gels from alkali-feldspars. Colloids and Surfaces A: Physicochemical and Engineering Aspects 2003, 216, 27-44. https://doi.org/10.1016/S0927-7757(02)00499-5

[20] Lin KL, Shiu HS, Shie JL, Cheng TW, Hwang CL. Effect of composition on characteristics of thin film transistor liquid crystal display (TFT-LCD) waste glass-metakaolin-based geopolymers. Construction and Building Materials 2012, 36, 501-507. https://doi.org/10.1016/i.conbuildmat.2012.05.018

[21] Pacheco-Torgal F, Jalali S, Castro Gomes JP. 13 - Utilization of mining wastes to produce geopolymer binders. In: Geopolymers. Provis, J.L.; van Deventer, J.S.J. Eds. Woodhead Publishing: 2009; pp. 267-293. https://doi.org/10.1533/9781845696382.2.267

[22] Rivera JF, Cuarán-Cuarán ZI, Vanegas-Bonilla N, Mejía de Gutiérrez R. Novel use of waste glass powder: Production of geopolymeric tiles. Advanced Powder Technology 2018, 29, 3448-3454. https://doi.org/10.1016/j.apt.2018.09.023

[23] Alonso S, Palomo A. Alkaline activation of metakaolin and calcium hydroxide mixtures: influence of temperature, activator concentration and solids ratio. Materials Letters 2001, 47, 55-62. https://doi.org/10.1016/S0167-577X(00)00212-3

[24] Novais RM, Ascensão G, Seabra MP, Labrincha JA. Waste glass from end-of-life fluorescent lamps as raw material in geopolymers. Waste Management 2016, 52, 245 255. https://doi.org/10.1016/j.wasman.2016.04.003

[25] Panias D, Giannopoulou IP, Perraki T. Effect of synthesis parameters on the mechanical properties of fly ash-based geopolymers. Colloids and Surfaces A: Physicochemical and Engineering Aspects 2007, 301, 246-254. https://doi.org/10.1016/i.colsurfa.2006.12.064

[26] Cyr M, Idir R, Poinot T. Properties of inorganic polymer (geopolymer) mortars made of glass cullet. Journal of Materials Science 2012, 47, 2782-2797. https://doi.org/10.1007/s10853-011-6107-2

[27] Pascual A, Tognonvi M, Tagnit-Hamou A. Waste glass powder-based alkali-activated mortar. International Journal of Research in Engineering and Technology 2014, 03, 32 36. https://doi.org/10.15623/ijret.2014.0325006

[28] Hajimohammadi A, Ngo T, Kashani A. Sustainable one-part geopolymer foams with glass fines versus sand as aggregates. Construction and Building Materials 2018, 171, 223-231. https://doi.org/10.1016/j.conbuildmat.2018.03.120

[29] Abdollahnejad Z, Zhang Z, Wang H, Mastali M. Comparative Study on the Drying Shrinkage and Mechanical Properties of Geopolymer Foam Concrete Incorporating Different Dosages of Fiber, Sand and Foam Agents. In: Proceedings of High Tech Concrete: Where Technology and Engineering Meet, Cham, 2018; pp. 42-48. https://doi.org/10.1007/978-3-319-59471-2 6

[30] Grassl P, Wong HS, Buenfeld NR. Influence of aggregate size and volume fraction on shrinkage induced micro-cracking of concrete and mortar. Cem. Concr. Res. 2010, 40, 85-93. https://doi.org/10.1016/i.cemconres.2009.09.012

[31] Rao GA. Long-term drying shrinkage of mortar - influence of silica fume and size of fine aggregate. Cement and Concrete Research 2001, 31, 171-175. https://doi.org/10.1016/S0008-8846(00)00347-1

[32] Carrasco, M.; Puertas, F.; Varga, C.; Torres, J.J.; Moreno, E.; Palomo, J.G. Re-use of urban and industrial glass waste to prepare alkaline cements. 2012.

[33] Puertas F, Torres-Carrasco M. Use of glass waste as an activator in the preparation of alkali-activated slag. Mechanical strength and paste characterisation. Cement and $\begin{array}{llll}\text { Concrete } & \text { Research } & \text { 95-104. }\end{array}$ https://doi.org/10.1016/j.cemconres.2013.12.005 
[34] Martinez-Lopez R, Ivan Escalante-Garcia J. Alkali activated composite binders of waste silica soda lime glass and blast furnace slag: Strength as a function of the composition. Construction and Building Materials 2016, 119, 119-129. https://doi.org/10.1016/i.conbuildmat.2016.05.064

[35] Puertas F. Cementos de escoriasactivadasalcalinamente: Situación actual y perspectivas de futuro. Mater. Constr. 1995, 45, 53-64. https://doi.org/10.3989/mc.1995.v45.i239.553

[36] Escalante García JI, Campos-Venegas K, Gorokhovsky A, Fernández A. Cementitious composites of pulverised fuel ash and blast furnace slag activated by sodium silicate: effect of Na20 concentration and modulus. Advances in Applied Ceramics 2006, 105, 201-208. https://doi.org/10.1179/174367606X120151

[37] Burciaga-Díaz 0, Magallanes-Rivera RX, Escalante-García JI. Alkali-activated slagmetakaolin pastes: strength, structural, and microstructural characterization. Journal of Sustainable Cement-Based Materials 2013, 2, 111-127. https://doi.org/10.1080/21650373.2013.801799

[38] Wang SD, Scrivener KL, Pratt PL. Factors affecting the strength of alkali-activated slag. Cement and Concrete Research 1994, 24, 1033-1043. https://doi.org/10.1016/00088846(94)90026-4

[39] Burciaga-Díaz O, Escalante-García JI. Structure, Mechanisms of Reaction, and Strength of an Alkali-Activated Blast-Furnace Slag. Journal of the American Ceramic Society 2013, 96, 3939-3948. https://doi.org/10.1111/jace.12620

[40] Técnica E, De Edificación S. Politécnica, U. Workshop on Environmental Impact of Buildings. 2013.

[41] Bagheri A, Nazari A. Compressive strength of high strength class C fly ash-based geopolymers with reactive granulated blast furnace slag aggregates designed by Taguchi method. Materials \& Design (1980-2015) 2014, 54, 483-490. https://doi.org/10.1016/i.matdes.2013.07.035

[42] Nazari A, Riahi S, Bagheri A. Designing water resistant lightweight geopolymers produced from waste materials. Materials \& Design 2012, 35, 296-302. https://doi.org/10.1016/j.matdes.2011.09.016

[43] Bakharev T, Sanjayan JG, Cheng YB. Effect of admixtures on properties of alkaliactivated slag concrete. Cement and Concrete Research 2000, 30, 1367-1374. https://doi.org/10.1016/S0008-8846(00)00349-5

[44] Tho-In T, Sata V, Boonserm K, Chindaprasirt P. Compressive strength and microstructure analysis of geopolymer paste using waste glass powder and fly ash. Journal of Cleaner Production 2018, 172, 2892-2898. https://doi.org/10.1016/j.jclepro.2017.11.125

[45] Silva PD, Sagoe-Crenstil K, Sirivivatnanon V. Kinetics of geopolymerization: Role of Al2O3 and SiO2. Cement and Concrete Research 2007, 37, 512-518. https://doi.org/10.1016/i.cemconres.2007.01.003

[46] Fletcher RA, MacKenzie KJD, Nicholson CL, Shimada S. The composition range of aluminosilicate geopolymers. Journal of the European Ceramic Society 2005, 25, 14711477. https://doi.org/10.1016/j.jeurceramsoc.2004.06.001

[47] Rattanasak U, Chindaprasirt P, Suwanvitaya P. Development of high volume rice husk ash alumino silicate composites. International Journal of Minerals, Metallurgy, and Materials 2010, 17, 654-659. https://doi.org/10.1007/s12613-010-0370-0

[48] Davidovits J. Geopolymers: Inorganic Polymeric New Materials. Journal of Thermal Analysis and Calorimetry 1991, 37, 1633-1656. https://doi.org/10.1007/BF01912193

[49] Chindaprasirt P, Rattanasak U, Vongvoradit P, Jenjirapanya S. Thermal treatment and utilization of Al-rich waste in high calcium fly ash geopolymeric materials. International Journal of Minerals, Metallurgy, and Materials 2012, 19, 872-878. https://doi.org/10.1007/s12613-012-0641-z 
[50] Temuujin J, van Riessen A, Williams R. Influence of calcium compounds on the mechanical properties of fly ash geopolymer pastes. Journal of Hazardous Materials 2009, 167, 82-88. https://doi.org/10.1016/j.jhazmat.2008.12.121

[51] Saha S, Rajasekaran C. Enhancement of the properties of fly ash based geopolymer paste by incorporating ground granulated blast furnace slag. Construction and Building Materials 2017, 146, 615-620. https://doi.org/10.1016/i.conbuildmat.2017.04.139

[52] Badanoiu AI, Al Saadi THA, Stoleriu S, Voicu G. Preparation and characterization of foamed geopolymers from waste glass and red mud. Construction and Building Materials 2015, 84, 284-293. https://doi.org/10.1016/i.conbuildmat.2015.03.004

[53] Guo Y, Zhang Y, Huang H, Meng K, Hu K, Hu P, Wang X, Zhang Z, Meng X. Novel glass ceramic foams materials based on red mud. Ceramics International 2014, 40, 6677 6683. https://doi.org/10.1016/j.ceramint.2013.11.128

[54] Zhang S, Keulen A, Arbi K, Ye G. Waste glass as partial mineral precursor in alkaliactivated slag/fly ash system. Cement and Concrete Research 2017, 102, 29-40. https://doi.org/10.1016/j.cemconres.2017.08.012

[55] Ravikumar D, Neithalath N. Effects of activator characteristics on the reaction product formation in slag binders activated using alkali silicate powder and $\mathrm{NaOH}$. Cement and Concrete Composites 2012, 34, 809-818. https://doi.org/10.1016/i.cemconcomp.2012.03.006

[56] Kutchko BG, Kim AG. Fly ash characterization by SEM-EDS. Fuel 2006, 85, 2537-2544. https://doi.org/10.1016/j.fuel.2006.05.016

[57] Dudas MJ, Warren CJ. Submicroscopic model of fly ash particles. Geoderma 1987, 40, 101-114. https://doi.org/10.1016/0016-7061(87)90016-4

[58] Yu Z. Microstructure development and transport properties of portland cement-fly ash binary systems, View of Service Life Predictions. TU Delft, Delft University of Technology, 2015.

[59] Peronius N, Sweeting TJ. On the correlation of minimum porosity with particle size distribution. Powder Technology 1985, 42, 113-121. https://doi.org/10.1016/00325910(85)80043-7

[60] Kastiukas G, Zhou X. Effects of waste glass on alkali-activated tungsten mining waste: composition and mechanical properties. Materials and Structures 2017, 50.https://doi.org/10.1617/s11527-017-1062-2 